\title{
Superior sagittal sinus thrombosis: an evaluation of the changes demonstrated on computed tomography
}

\author{
D. P. E. K I N G S L E Y, B. E. K E N D A L L, A N D I. F. MO S E L E Y \\ From the National Hospital for Nervous Diseases, Queen Square, London
}

SUMMARY Five female patients, all either on contraceptive medication or in the postpartum period, with angiographically confirmed superior sagittal sinus thrombosis have been scanned. CAT appearances are nonspecific, but when taken in conjuction with the symptoms should suggest the possible diagnosis. The most consistent appearance was of diffuse cerebral swelling with subsequent return to normal. Bilateral low attenuation lesions with haemorrhagic areas were noted in one patient.

An extensive literature has accumulated on superior sagittal sinus and cortical vein thrombosis since the condition was first described 130 years ago. This is, however, undoubtedly more common than the published reports suggest, since it may simulate closely other diseases in both its clinical and radiological features, and may not be recognised at postmortem examination unless specifically looked for.

The diagnosis is made by angiography (Huhn, 1957) but delayed films (Fig. 1) with simultaneous bilateral internal carotid injection (Yasargil and Damur, 1974) or cross compression may be required. The value of computerised tomography (CAT) scanning has not so far been assessed, either in the initial diagnosis or in the subsequent follow-up of such cases. During the past three years we have examined five cases of superior sagittal sinus thrombosis by CAT, four of whom were scanned within one week of the presenting symptoms. Two patients underwent two or more scans. The diagnosis was made in all instances by angiography, and the relevant clinical and diagnostic features are documented in the Table.

\section{Results}

All five patients were scanned at least once, three were scanned twice, and one three times. The time interval between the ictus and the first CAT scan varied between three and 21 days, four being

Address for reprint requests: Dr D. P. E. Kingsley, X-Ray Department, The London Hospital, Whitechapel, London E1 1 BB.

Accepted 12 June 1978 carried out within the first week. In all but one patient, the angiogram was performed within two days of the CAT scan. All four patients scanned within the first week either showed small ventricles at the time of the initial scan, or ventricular enlargement on subsequent scans undertaken 14 and 16 days later, respectively. One of these patients (case 4) showed slight swelling of one hemisphere. The other (case 2), in whom the clinical picture was most severe, was found to have very clearly defined biparietal low attenuation areas, with haemorrhage, when scanned seven days after the ictus. Subsequent scans at 21 and 32 days showed progressive resolution of these lesions.

One patient was admitted only three weeks after the ictus and, therefore, no early scan was obtained, but two scans at 21 and 31 days after the ictus were normal and did not demonstrate any change in ventricular size. A similar lack of change in ventricular size was seen in the second and third scans of case 2, undertaken at 21 and 32 days respectively.

One patient was given intravenous contrast medium as well as xenon anaesthesia, and no change was seen with either of these contrast agents.

\section{Discussion}

The clinical picture of severe headaches with subsequent onset of paresis noted in all patients was consistent with the diagnosis, and this was confirmed on angiography. Epilepsy, which is usually considered to be a prominent feature, was not present in three of our cases. Papilloedema was 


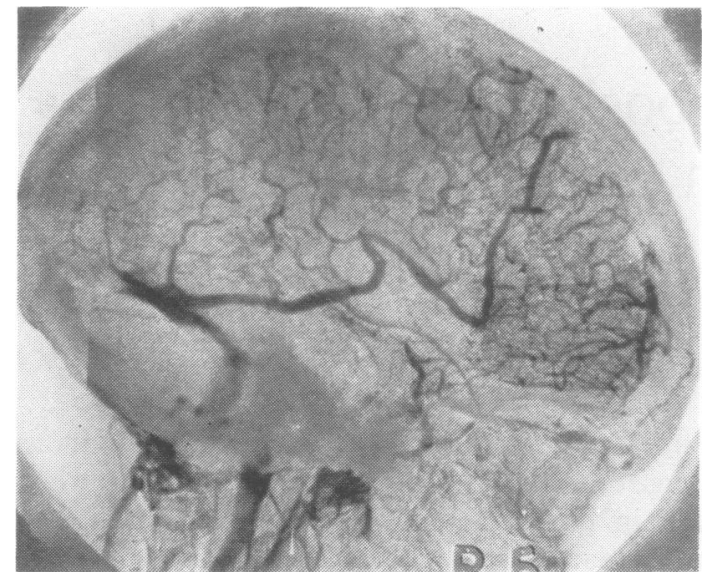

(a)

Fig. 1 Case 3. Carotid angiography. Lateral (a) and anterior-posterior $(b)$ views with cross compression nine days after ictus showing thrombosis of the sagittal sinus with venous drainage laterally into the sigmoid sinus.

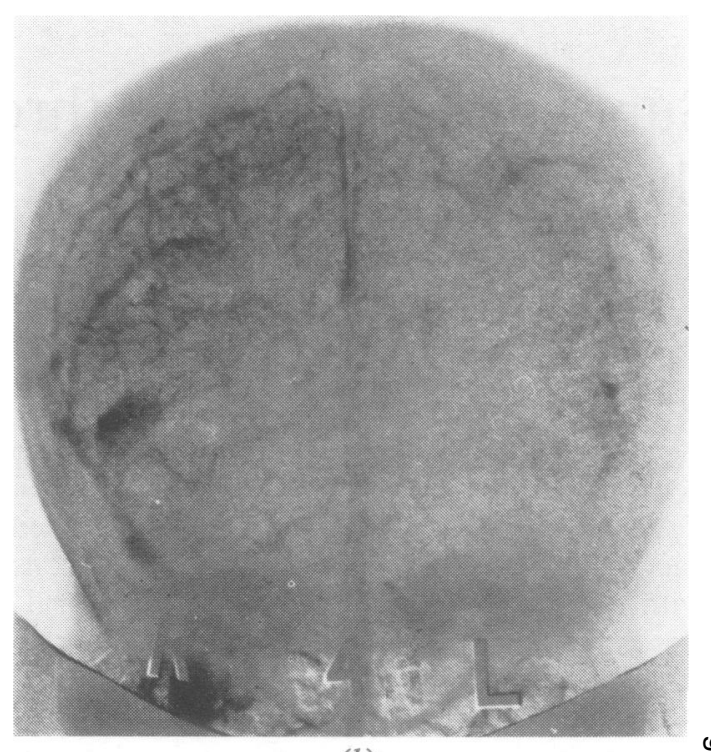

(b)

Table Clinical and diagnostic features of patients studied

\begin{tabular}{|c|c|c|c|c|c|c|}
\hline Case & $\begin{array}{l}\text { Age } \\
(y r)\end{array}$ & & $\begin{array}{l}\text { Days from ictus } \\
\text { Examination }\end{array}$ & Angiogram & $C A T$ scan & $C A T$ findings \\
\hline 1 & 30 & $\begin{array}{l}\text { Post-partum } \\
3 \text { day headache } \\
\text { Right hemiparesis } \\
\text { Bilateral upper hemisphere field } \\
\text { defect }\end{array}$ & 3 & 13 & 3 & Ventricles small \\
\hline 2 & 43 & $\begin{array}{l}\text { On contraceptive pill } \\
3 \text { day headache. Focal fit } \\
\text { Tetraparesis } \\
\text { Slight papilloedema }\end{array}$ & 4 & 4 & $\begin{array}{r}7 \\
21 \\
32\end{array}$ & $\begin{array}{l}\text { Ventricles normal } \\
\text { Biparietal low attenuation and } \\
\text { haemorrhage } \\
\text { Ventricles larger } \\
\text { Resolving hemisphere lesions } \\
\text { Ventricles unchanged } \\
\text { Further resolution of hemisphere } \\
\text { lesions }\end{array}$ \\
\hline 3 & 21 & $\begin{array}{l}\text { Post-partum } \\
5 \text { day headache } \\
\text { Dysphasia } \\
\text { Right hemiparesis } \\
\text { Papilloedema }\end{array}$ & 7 & 9 & $\begin{array}{l}7 \\
9 \text { (xenon) }\end{array}$ & $\begin{array}{l}\text { Ventricles small } \\
\text { No change }\end{array}$ \\
\hline 4 & 22 & $\begin{array}{l}\text { On contraceptive pill } \\
7 \text { day headache } \\
\text { Left hemiparesis } \\
\text { Focal fits } \\
\text { Early papilloedema }\end{array}$ & 7 & 9 & $\begin{array}{r}7 \\
23\end{array}$ & $\begin{array}{l}\text { Ventricles small } \\
\text { Right hemisphere swelling } \\
\text { Ventricles larger }\end{array}$ \\
\hline 5 & 36 & $\begin{array}{l}\text { On contraceptive pill } \\
3 \text { weeks headache } \\
\text { Right hemiparesis } \\
\text { Bilateral papilloedema }\end{array}$ & 21 & 23 & $\begin{array}{l}21 \\
31\end{array}$ & $\begin{array}{l}\text { Ventricles normal } \\
\text { No change }\end{array}$ \\
\hline
\end{tabular}

present in four of the five cases, but not in the patient first examined only three days after the ictus.

CAT findings are consistent in the five cases when the length of time between the ictus and the scan is taken into consideration. In the acute phase of the condition, the ventricles appear smaller than on subsequent scans undertaken two weeks later, and in three of the five patients the ventricles were thought to be smaller than normal (Fig. 2). Biparietal haemorrhagic lesions were seen in one patient only, and at the time of the 


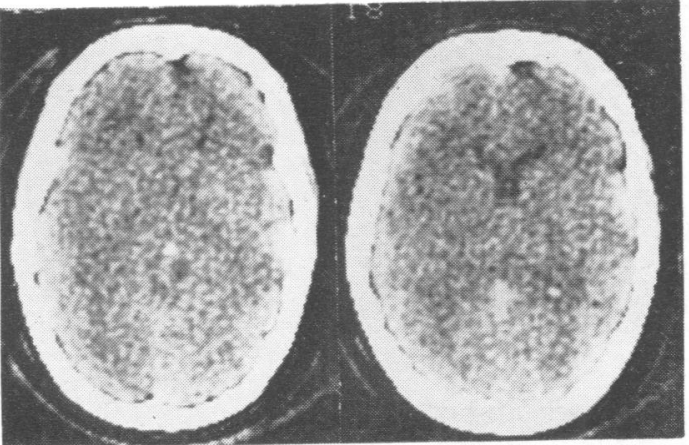

(a)

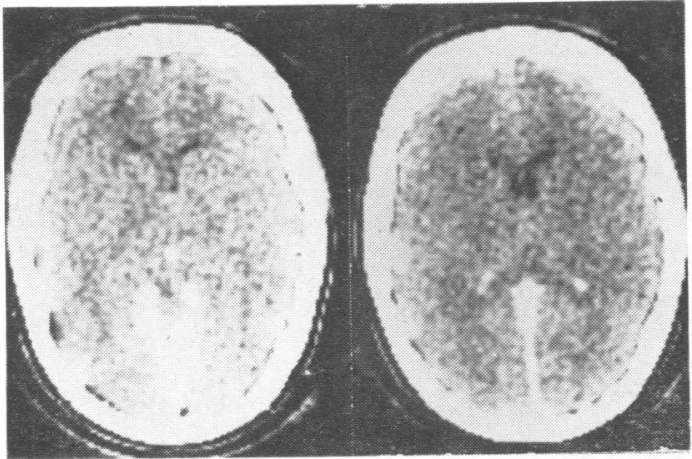

(b)

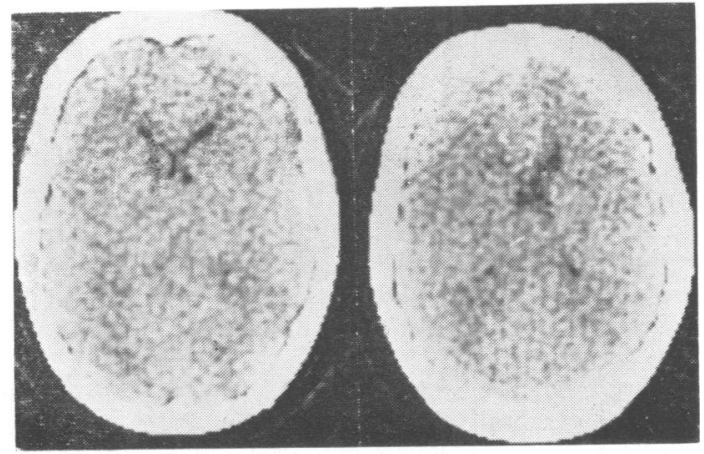

(c)

first scan the ventricles were considered to be of normal size (Fig. 3). Subsequent scans showed enlargement of the ventricles, and it is probable that the initial ventricular size in this case indicated bilateral cerebral swelling. Low attenuation which may occur because of oedema or infarction may, however, be absent despite the swelling. This is probably caused by a diffuse distribution of fluid which allows a fall of attenuation to remain within normal limits of white matter values.
Fig. 2 Case 3. CAT scan seven days after ictus (a) unenhanced, (b) enhanced, and (c) two days later with xenon anaesthesia demonstrating small ventricles, but no change after intravenous contrast medium or xenon anaesthesia.

Although small ventricles are frequently encountered on CAT scanning, superior sagittal sinus thrombosis is a rare cause, benign intracranial hypertension and diffuse inflammatory and posttraumatic conditions being more common, while less common causes include bilateral isodense subdural haematomas, epileptics on treatment with phenytoin, and $\mathrm{CO}_{2}$ narcosis. However, of these five female patients, three were on the contraceptive pill and two had very recently given birth, 


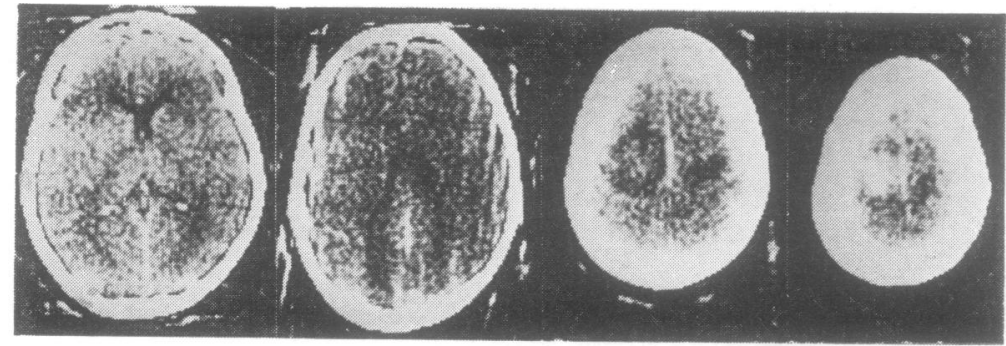

(a)

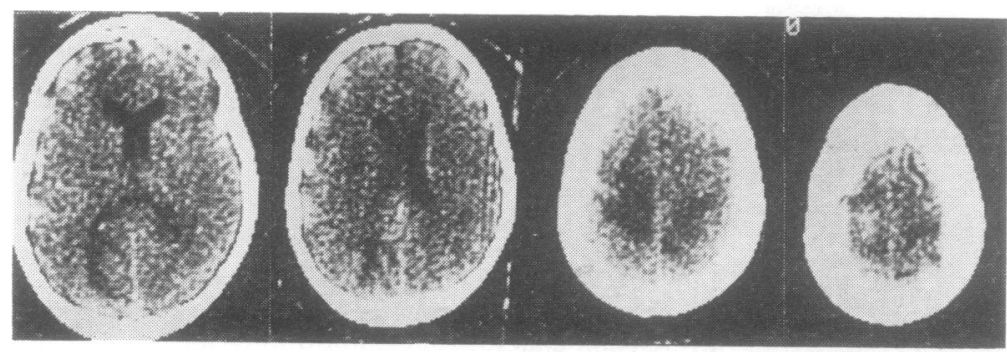

(b)

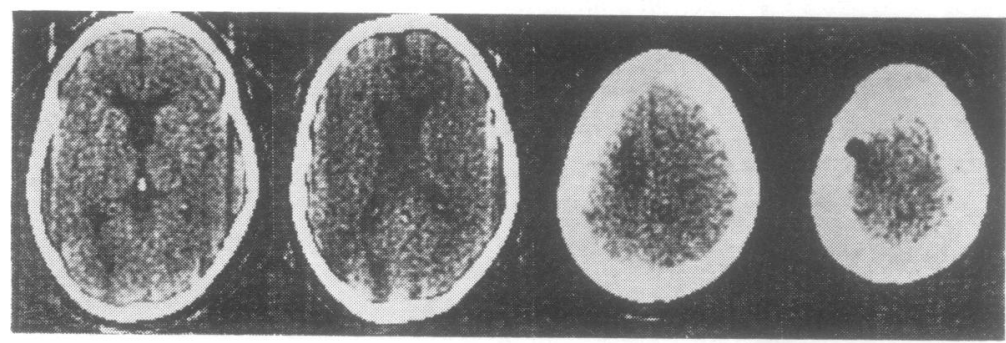

(c)

two factors well known to be associated with sinus thrombosis.

There is no established lower limit of normal ventricular size, and subsequent scans showing an increase in size are necessary for the diagnosis of cerebral swelling. However, where the history is suggestive, the demonstration of small ventricles should raise the suspicion of venous thrombosis and suggest the need for angiography to confirm the diagnosis.

\section{References} $177,48-61$. St Louis.
Fig. 3 Case 2. (a) Scan seven days after ictus showing "small" ventricles originally described as normal with biparietal low attenuation and left parietal haemorrhage; (b) same patient 21 days after ictus, and (c) 37 days after ictus showing return of ventricles to normal with progressive resolution of biparietal lesions.

Huhn, A. (1957). Die Bedeutung der Serienangiographie fur die Diagnose der Hirmvenen und Sinusthrombose. Deutsche Zietschrift Nervenheildt,

Yasargil, M. G., and Damur, M. (1974). Thrombosis of the cerebral veins and dural sinuses. In Radiology of the Skull and Brain, vol. 2, pp. 2376-2400. Edited by T. H. Newton and D. G. Potts. C. V. Mo:by: 